\title{
High-throughput NIR-chemometric method for direct quantification of loratadine in powder blends for tableting and tablets
}

\author{
Bianca SYLVESTER, Alina PORFIRE, Marcela ACHIM, Ioan TOMUTA \\ Department of Pharmaceutical Technology and Biopharmacy, Faculty of Pharmacy, \\ "Iuliu Hatieganu" University of Medicine and Pharmacy, Cluj-Napoca, Romania
}

\begin{abstract}
Objectives. The aim of this study was to develop and validate a NIR-chemometric method for direct quantification of loratadine in powder blends for tableting and tablets, without any sample preparation.

Material and methods. Calibration samples were prepared according to an experimental design with 1 variable and 5 level, containing from 8 to $12 \mathrm{mg}$ loratadine/tablet.

Outcomes. For the powder blends, the model generated with the use of spectral range 9,000-4,000 cm-1 and FD+SNV pre-treatment method had the best results, considering the number of PLS factors 9, R2 $=0.984$ and RMSECV $=0.267 \%$. For the tablets, the model using the spectral range 11,100-7,128 cm-1 and mMN pre-treatment method had the best results, considering the number of PLS factors $10, R 2=0.985$ and RMSECV $=0.170 \mathrm{mg}$. Using these calibration models, the method was fully validated according to the ICH guidance. For both powder blends and tablets, the best accuracy was obtained at the concentration level of $10 \mathrm{mg} /$ tablet and the relative bias had values between $0.05 \%$ and $1.98 \%$ respectively $-0.360 \%$ and $0.618 \%$.

Conclusions. The NIR-chemometric method has good reproducibility and satisfactory accuracy and linearity profiles, indicating that this method could be used for direct determination of loratadine in powder blends for tableting and tablets, without any sample preparation.
\end{abstract}

Keywords: loratadine assay, near infrared spectroscopy, chemometry, process analytical technology

\section{INTRODUCTION}

Near infrared spectroscopy has gained wide acceptance within the pharmaceutical industry, thanks to its broad range of applications, comprising analysis of intact dosage forms and process monitoring (1), with the possibility of being applied for the analysis of liquid, slurry, powdered or solid samples. The use of NIR in industrial practice has become more popular thanks to Karl Norris, who recognized its potential use for measurements of certain types of food, agricultural components (2) and product quality control.

Branches as pharmaceutical technology, microbiology, toxicology, counterfeit detection, determination of physicochemical properties, stability testing and also quality control of a final product have adopted NIR spectroscopy as a crucial method. Pharmaceutical technology needs NIR spectroscopy for implementation of in- and on-line process control in many phases of the manufacturing process $(3,4)$, such as identification 
and quality testing of raw materials, monitoring of granulating-drying process, compact hardness during the granulating-drying process, powder flow and blend uniformity of powders for tableting and simultaneous identification and quantification of API in intermediate products and final products $(5,6)$.

In 2003, the Food and Drug Administration Agency (FDA) announced Pharmaceutical Current Good Manufacturing Practices (cGMPs) for the $21^{\text {st }}$ century, this document being recommended and respected all over the world.

Generally, it is based on a risk approach of assurance of a pharmaceutical product quality and provides an implementation of Process Analytical Technology (PAT) in the process control of rawmaterials, intermediate and final products (7)

NIR spectroscopy is recognized as a Process Analytical Technology tool. NIR spectra can be obtained without sample preparation and due to this fact NIR has become one of the most promising spectroscopic tools for process monitoring and manufacturing control in the pharmaceutical industry (8). In order to interpret the NIR spectra, chemometric techniques have gained enormous significance, due to their ability to process a vast amount of data and their capacity of extracting the information of interest and improving the quality of the results (9).

The assay methods for loratadine in pharmaceutical preparations developed and validated so far were either UV spectrometry (10), colorimetry (11), spectrofluorimetry (12) atomic absorption spectrometry (13), densitometry (14), capillary electrophoresis (15) and high performance liquid chromatography $(10,16,17)$. All these methods rely on intensive sample pre-treatment, use of proper organic solvents and some of them, can be time consuming. NIR spectroscopy combined with chemometrical programs has the advantage of being rapid, noninvasive and does not require any sample preparation. The NIR method reduces sampling errors and provides the possibility of end-point determination, leading to a potentially significant improvement over the conventional analytical methods (6).

A proper interpretation of results obtained after application of NIR spectroscopy in quality as well as quantity determination, is a difficult task and it involves choosing the best from many spectra obtained by pre-treatments steps, calibration and validation processes, for further calculation. The validation of the NIR method is mandatory in order to give enough guarantees that each of the future results during routine use will be close enough to the true value $(18,19)$. The aim of this research was to develop and validate a NIR chemometric method for direct and simultaneous identification and quantification of loratadine in powder blends (as intermediate) and tablets.

\section{MATERIALS AND METHODS}

\section{Materials}

Loratadine was purchased from Labormed Pharma, Romania. Lactose monohydrate (Tablettose 80, average particle size $177 \mu \mathrm{m}$ ) was provided by Meggle, Germany. Microcrystalline cellulose (Vivapur PH 102, average particle size 100 
TABLE 1. Composition of calibration and validation samples

\begin{tabular}{|l|c|c|c|c|c|}
\hline Concentration level & $\begin{array}{c}1 \\
\end{array}$ & $\begin{array}{c}2 \\
90 \%\end{array}$ & $\begin{array}{c}3 \\
900 \%\end{array}$ & $\begin{array}{c}4 \\
110 \%\end{array}$ & $\begin{array}{c}5 \\
120 \%\end{array}$ \\
\hline Loratadine (mg) & 8.00 & 9.00 & 10.00 & 11.00 & 12.00 \\
\hline Lactose monohydrate (mg) & 52.25 & 51.75 & 51.25 & 50.75 & 50.25 \\
\hline Microcrystalline cellulose (mg) & 21.00 & 20.50 & 20.00 & 19.50 & 19.00 \\
\hline Pregelatinized starch (mg) & 15.00 & 15.00 & 15.00 & 15.00 & 15.00 \\
\hline Sodium starch glycolate (mg) & 3.00 & 3.00 & 3.00 & 3.00 & 3.00 \\
\hline Silicon dioxide (mg) & 0.25 & 0.25 & 0.25 & 0.25 & 0.25 \\
\hline Magnesium stearates (mg) & 0.50 & 0.50 & 0.50 & 0.50 & 0.50 \\
\hline Tablet weight (mg) & 100.00 & 100.00 & 100.00 & 100.00 & 100.00 \\
\hline
\end{tabular}

Calibration samples: levels 1-2-3-4-5; validation samples: levels 2-3-4.

$\mu \mathrm{m})$, sodium starch glycolate

(Vivastar) and silicon dioxide

(Aerosil) were supplied by JRS

Pharma, Germany. Pregelatinized

starch (Starch 1500) was provided

by Colorcon, United Kingdom and magnesium stearate by Undesa,

Spain.

\section{Preparation of powder blends for} tableting and tablets

Loratadine, lactose $(51.25 \%, \mathrm{w} / \mathrm{w})$, microcrystalline cellulose

$(20 \%, w / w)$, pregelatinized starch $(15 \%, w / w)$, sodium starch glycolate $(3 \%, \mathrm{w} / \mathrm{w})$ and silicon dioxide $(0.25 \%, w / w)$ were homogenized using a planetary mixer (PRS type, Erweka, Germany) for 10 minutes. Magnesium stearate $(0.50 \%, \mathrm{w} / \mathrm{w})$ was added and mixing was continued for one more minutes. The powder blend was then passed through a 0.600 $\mathrm{mm}$ sieve. The mixture composition was designed for a tablet weight of $100 \mathrm{mg}$ and an amount of active pharmaceutical ingredient of $10 \mathrm{mg}$ $(10 \%, w / w)$. This formulation will be further considered the $100 \%$ active content formulation. A total of $100 \mathrm{mg}$ of this tableting powder was filled in a die $(\varnothing 7 \mathrm{~mm})$ and then compressed using an eccentric tablet press (Korsch, Germany).

\section{Calibration and validation protocol} An orthogonal experimental design with 1 factor (loratadine) and 5 levels (5 concentrations ranging between $80 \%$ and $120 \%$ ) was used to generate the calibration set (Table 1).

Each formulation contained 8, 9, 10,11 and $12 \mathrm{mg}$ respectively of loratadine corresponding to 80,90 , 100,110 and $120 \%$ loradatine content. Three independent batches were manufactured per formulation type in three different days, resulting in 15 different batches of calibration samples. In order to validate the NIR method, 3 independent series (corresponding to 3 different days) were prepared at 3 concentration levels (corresponding to 90, 100, 110\% active substance content). For each concentration level 4 independent

TABLE 2. Calibration and validation strategy

\begin{tabular}{|c|c|c|c|c|c|c|c|}
\hline \multirow{2}{*}{$\begin{array}{c}\text { Concentration } \\
\text { level }\end{array}$} & \multicolumn{2}{|c|}{ Series 1 } & \multicolumn{2}{c|}{ Series 2 } & \multicolumn{2}{c|}{ Series 3 } \\
\cline { 2 - 8 } & Calibration & Validation & Calibration & Validation & Calibration & Validation \\
\hline 1 & $80 \%$ & 1 & 0 & 1 & 0 & 1 & 0 \\
\hline 2 & $90 \%$ & 1 & 4 & 1 & 4 & 1 & 4 \\
\hline 3 & $100 \%$ & 1 & 4 & 1 & 4 & 1 & 4 \\
\hline 4 & $110 \%$ & 1 & 4 & 1 & 4 & 1 & 4 \\
\hline 5 & $120 \%$ & 1 & 0 & 1 & 0 & 1 & 0 \\
\hline
\end{tabular}


formulations were prepared and analyzed (12 formulations/day). The validation was performed according to the strategy proposed by Hubert et al. (20-23).

The calibration and validation strategies are summarized in Table 2.

\section{NIR spectra recording}

NIR spectra for the powder blends were recorded using an Antaris II FTNIR analyzer (Thermo Scientific, USA) in Transflectance Sampling configuration. Each spectrum was acquired by integrating 32 scans over a wavenumber between 10,000 to $4,000 \mathrm{~cm}^{-1}$ with $16 \mathrm{~cm}^{-1}$ resolution. NIR spectra for the tablets were recorded using a MPA-NIR analyzer (Bruker Optics, Germany) in Transmittance Sampling configuration. Each transmittance spectrum was acquired by integrating 32 scans taken over a wavenumber between 12,500 to $5,800 \mathrm{~cm}^{-1}$ with $16 \mathrm{~cm}^{-1}$ resolution.
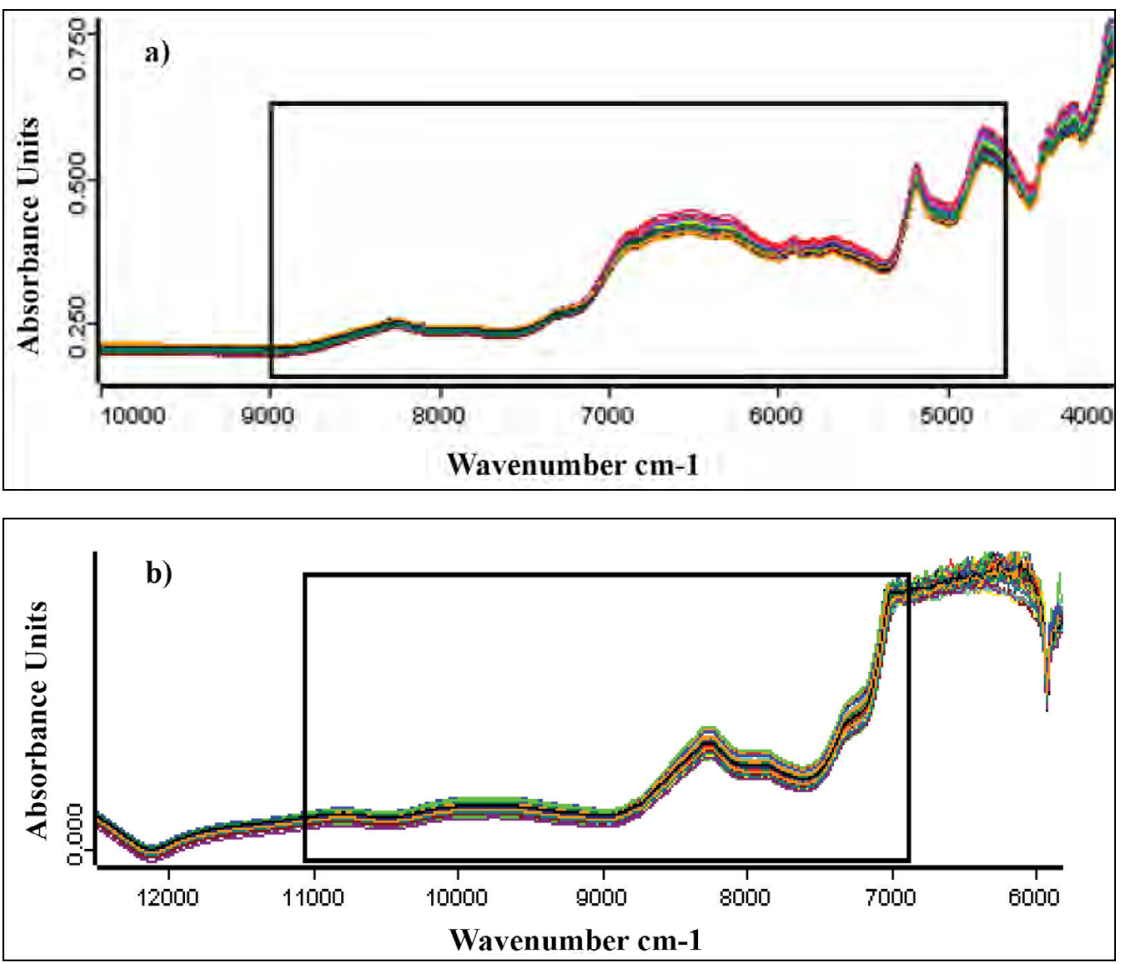

FIGURE 1. NIR spectra of (a) loratadine powder blends for tableting and (b) loratadine tablets, used for API assay calibration. The spectral areas chosen for the models are highlighted.

\section{NIR spectra processing}

While mid-IR spectra and especially the absorbance bands are directly interpretable due to chemical peak specificity, NIR spectra are difficult to interpret. Therefore, the use of chemometrics is required (24). For this purpose, different spectral pre-treatments in combination with different spectral ranges containing strong bands of loratadine were analyzed. The spectral pretreatments tested in order to find the best calibration model included vector normalization (SNV), straight line subtraction (SLS), min-max normalization (mMN), multiplicative scatter correction (MSC), first derivative (FD) and combinations of two pre-processing methods: FD followed by SNV, FD followed by MSC or FD followed by SLS. FD was obtained by applying Savitzky-Golay algorithm.

Multivariate calibration was applied to chemometric approaches based on PLS (Partial Least Squares) regression using Opus Quant (Bruker Optics, Germany) software. The models were tested by full cross-validation.

\section{RESULTS AND DISCUSSIONS}

The aim of this research was to develop a method suitable for the direct quantification of loratadine, both from powder blends for tableting and tablets. For this purpose a NIR-chemometric method was developed and validated according to ICH Q2 (R1) guideline requirements (25).

\section{Model development}

Constructing an appropriate calibration set requires expanding chemical variability in the samples in order to encompass a wide enough concentration range. Incorporating chemical variability 
TABLE 3. Type of spectral pre-treatment, spectral range selected, number of PLS factors and RMSECV of different models for loratadine assay in powder blends. The chosen model ( $g$ ) is highlighted.

\begin{tabular}{|l|c|c|c|c|c|c|c|c|}
\hline \multicolumn{1}{|c|}{ Model } & $\mathrm{a}$ & $\mathrm{b}$ & $\mathrm{c}$ & $\mathrm{d}$ & $\mathrm{e}$ & $\mathrm{f}$ & $\mathbf{g}$ & $\mathrm{h}$ \\
\hline Pre-treatment & None & $\mathrm{SLS}$ & $\mathrm{FD}+\mathrm{SNV}$ & $\mathrm{FD}+\mathrm{SLS}$ & $\mathrm{SD}$ & FD+SLS & FD+SNV & SD \\
\hline Spectral range $\left(\mathrm{cm}^{-1}\right)^{*}$ & 1 & 1 & 1 & 1 & 2 & 2 & $\mathbf{2}$ & 3 \\
\hline Number of PLS factors & 9 & 8 & 8 & 8 & 7 & 9 & $\mathbf{9}$ & 5 \\
\hline $\mathrm{R}^{2}$ & 92.94 & 92.15 & 93.19 & 93.36 & 92.70 & 95.85 & $\mathbf{9 6 . 4 2}$ & 93.3 \\
\hline RMSECV (\%) & 0.410 & 0.373 & 0.403 & 0.398 & 0.382 & 0.288 & $\mathbf{0 . 2 6 7}$ & 0.366 \\
\hline
\end{tabular}

*Spectral range: $1: 9,000-4,750 \mathrm{~cm}^{-1} ; 2: 9,000-4,000 \mathrm{~cm}^{-1} ; 3: 9,000-4,800 \mathrm{~cm}^{-1}$.

TABLE 4. Type of spectral pre-treatment, spectral range selected, number of PLS factors and RMSECV of different models for loratadine assay in tablets. The chosen model (e) is highlighted.

\begin{tabular}{|l|c|c|c|c|c|c|c|c|}
\hline \multicolumn{1}{|c|}{ Model } & $\mathrm{a}$ & $\mathrm{b}$ & $\mathrm{c}$ & $\mathrm{d}$ & $\mathbf{e}$ & $\mathrm{f}$ & $\mathrm{g}$ & $\mathrm{h}$ \\
\hline Pre-treatment & None & $\mathrm{SNV}$ & $\mathrm{SLS}$ & $\mathrm{mMN}$ & $\mathrm{COE}$ & $\mathrm{SD}$ & FD+MSC & FS+SLS \\
\hline Spectral range $\left(\mathrm{cm}^{-1}\right)$ & 1 & 1 & 1 & $\mathbf{1}$ & $\mathbf{2}$ & $\mathbf{2}$ & 2 & 2 \\
\hline Number of PLS factors & 9 & 9 & 9 & $\mathbf{1 0}$ & $\mathbf{8}$ & 10 & 10 & 6 \\
\hline $\mathrm{R}^{2}$ & 96.77 & 98.58 & 98.24 & $\mathbf{9 8 . 5 6}$ & 97.30 & 98.02 & 98.38 & 97.97 \\
\hline RMSECV (mg) & 0.254 & 0.170 & 0.188 & $\mathbf{0 . 1 7 0}$ & 0.232 & 0.199 & 0.180 & 0.201 \\
\hline
\end{tabular}

*Spectral range: $1: 11,100-7,128 \mathrm{~cm}^{-1} ; 2: 10,455-7,529 \mathrm{~cm}^{-1}$.

The models chosen to be the best fit were subsequently validated according to current pharmaceutical requirements.

TABLE 5. Validation results of NIR method for loratadine assay in powder blends

\begin{tabular}{|c|c|c|c|c|c|}
\hline \multirow{2}{*}{$\begin{array}{c}\text { Concentration level } \\
\text { (\% loratadine) }\end{array}$} & \multirow{2}{*}{$\begin{array}{c}\text { Mean loratadine } \\
\text { content (\%) }\end{array}$} & Trueness & \multicolumn{2}{|c|}{ Precision } & Accuracy \\
\cline { 3 - 6 } & & Recovery (\%) & $\begin{array}{c}\text { Repeatability } \\
(\text { RSD \%) }\end{array}$ & $\begin{array}{c}\text { Intermediate } \\
\text { precision (RSD \%) }\end{array}$ & $\begin{array}{c}\text { Tolerance limits } \\
(\% \mathrm{w} / \mathrm{w})\end{array}$ \\
\hline 9 & 9.18 & 101.98 & 2.89 & 3.04 & {$[8.52 ; 9.83]$} \\
\hline 10 & 10.20 & 102.01 & 2.28 & 3.52 & {$[9.09 ; 11.30]$} \\
\hline 11 & 11.00 & 100.05 & 1.30 & 1.88 & {$[10.42 ; 11.59]$} \\
\hline
\end{tabular}

TABLE 6. Validation results of NIR method for loratadine assay in tablets

\begin{tabular}{|c|c|c|c|c|c|}
\hline \multirow{2}{*}{$\begin{array}{l}\text { Concentration level } \\
\text { (mg loratadine) }\end{array}$} & \multirow{2}{*}{$\begin{array}{c}\text { Mean } \\
\text { loratadine } \\
\text { content (\%) }\end{array}$} & \multirow{2}{*}{$\begin{array}{c}\text { Trueness } \\
\text { Recovery (\%) }\end{array}$} & \multicolumn{2}{|c|}{ Precision } & \multirow{2}{*}{$\begin{array}{c}\text { Accuracy } \\
\text { Tolerance limits } \\
\text { (mg/tablet) }\end{array}$} \\
\hline & & & $\begin{array}{c}\text { Repeatability } \\
\text { (RSD \%) }\end{array}$ & $\begin{array}{c}\text { Intermediate } \\
\text { precision (RSD \%) }\end{array}$ & \\
\hline 9 & 9.05 & 100.55 & 0.384 & 0.393 & [8.63; 9.47] \\
\hline 10 & 10.03 & 100.30 & 0.188 & 0.185 & {$[9.54 ; 10.52]$} \\
\hline 11 & 10.96 & 99.63 & 0.187 & 0.162 & {$[10.34 ; 11.58]$} \\
\hline
\end{tabular}

into the calibration set involves preparing laboratory samples spanning the desired content range for the API (9). Each formulation prepared for the calibration set contained 8, 9, 10, 11 and $12 \mathrm{mg}$ respectively of loratadine corresponding to $80,90,100,110$ and $120 \%$ loratadine content.

The calibration model was built using three independent series of loratadine powder blends respectively tablet batches, prepared in three different days. Ten different powder blends respectively tablets were analyzed by NIR spectroscopy using the reflectance technique for powder blends and the transmittance technique for tablets. Model development for loratadine assay implied checking different spectral pre-treatment methods in combination with different spectral ranges. The NIR spectra of the loratadine powder blends respectively tablets are shown in Fig 1. The higher frequency part of the spectra was used for the development of the model. The spectral regions for loratadine assay in both powder blends $(9,000-4,750$ $\left.\mathrm{cm}^{-1}\right)$ and tablets $(11,100-7,128$ $\mathrm{cm}^{-1}$ ) used in the analysis were selected based on this criteria, before applying any spectral pre-treatment method.

PLS regression was applied to the calibration set and cross validation procedure was used for the determination of PLS factors (main components). The choice of an adequate number of factors is essential, in order to avoid the "over fitting" phenomenon. The model with the biggest predictive potential was selected according to conventional criteria: low root mean square error of cross 
validation (RMSECV), high

correlation coefficient $\left(R^{2}\right)$ and low number of PLS (26). Table 3 shows the main characteristics of 8 potential models for loratadine assay in powder blends. Based on this criteria, for the powder blends, the model generated with the use of spectral range $9,000-4,000 \mathrm{~cm}^{-1}$ and FD+SNV pre-treatment method had the best results, considering the number of PLS factors $9, R^{2}=$ 0.984 and RMSECV $0.267 \%$.

Table 4 summarizes the main characteristics for the potential models of loratadine assay in tablets. The model generated with the use of spectral range 11,100 $7,128 \mathrm{~cm}^{-1}$ and $\mathrm{mMN}$ pre-treatment method had the best results, considering the number of PLS factors $10, R^{2}=0.985$ and RMSECV $=0.170 \mathrm{mg}$.

Validation of the method

The validation protocol was realized according to ICH Q2 (R2) guideline requirements and included accuracy, precision, linearity and range of application. The validation results of NIR method for loratadine assay are shown in Tables 5 and 6 respectively.

Accuracy represents the total error concept, systematic error plus random error, and according to Hubert et al., cited in (27), an accuracy profile based on total error concept meets the ICH Q2 (R2) guideline requirements. Fig. 2 illustrates the accuracy profiles of the method.

The trueness of the method was evaluated by calculating the recovery, which had good values (close to $100 \%$ ) for all concentration levels, for both powder blends for tableting and tablets. The precision of the method was calculated based on two parameters, repeatability and intermediate precision at the three content levels taken into account for validation protocol (28). The linearity profile was obtained by plotting the calculated concentrations of the validation samples as a function of the introduced concentrations (27). The linearity profiles of the chosen models are illustrated in Fig. 3.

The acceptance limits were set at \pm 5 for the tablets and \pm 10 for the powder blends, the $\beta$-expectation tolerance limits were included in

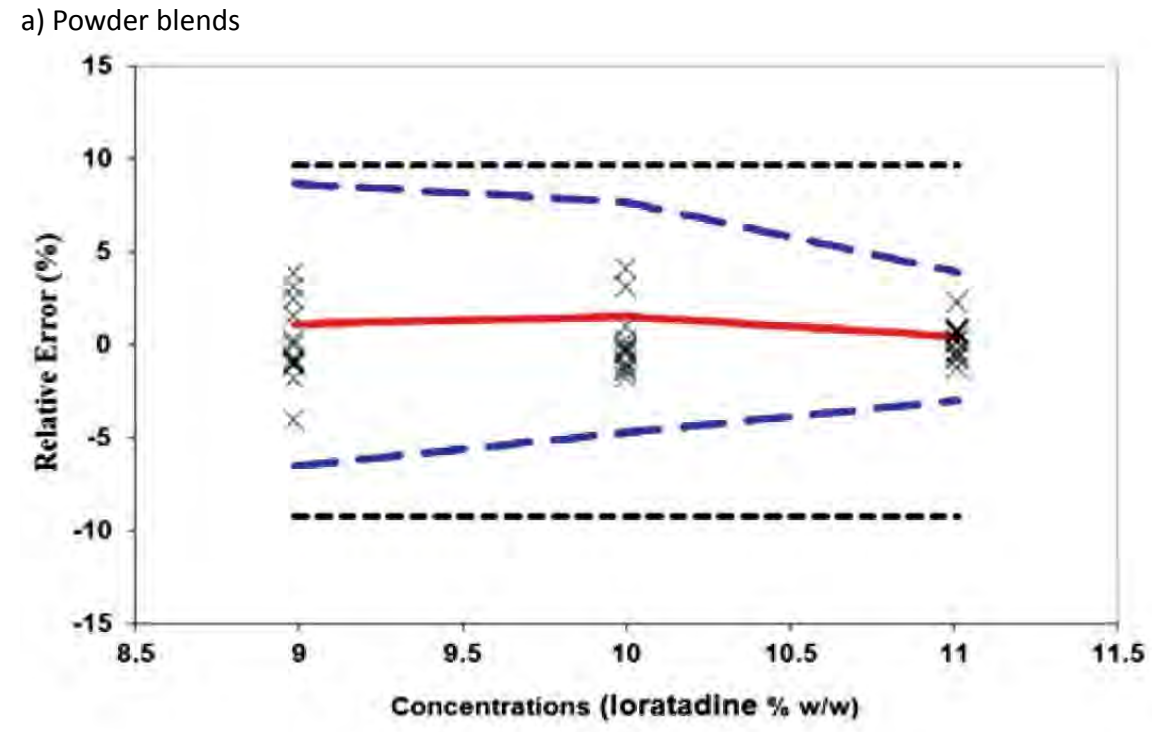

b) Tablets

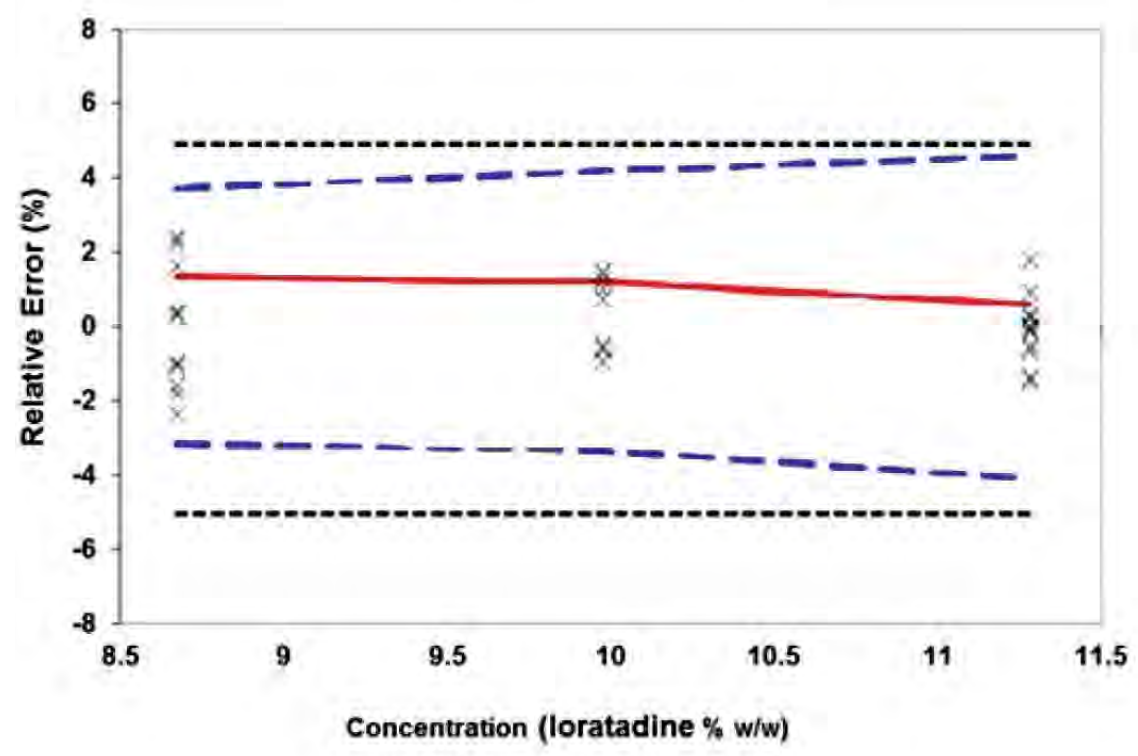

FIGURE 2. The accuracy profile obtained for the NIR-chemometric method for powder blends (a) and tablets (b) these intervals. The largest relative tolerance $(-8.835 \%, 12.855 \%)$ was obtained at the middle loratadine concentration level (10 mg/tablet) for the powder blends, respectively $(-6.018 \%, 5.297 \%)$ at the highest loratadine concentration level (11 mg/tablet) for the tablets. For the powder blends, the best accuracy was obtained at the concentration level of $10 \mathrm{mg} /$ tablet and the relative bias has values between $0.05 \%$ and $1.98 \%$ for all the concentration levels. In terms a) Powder blends 
a) Powder blends

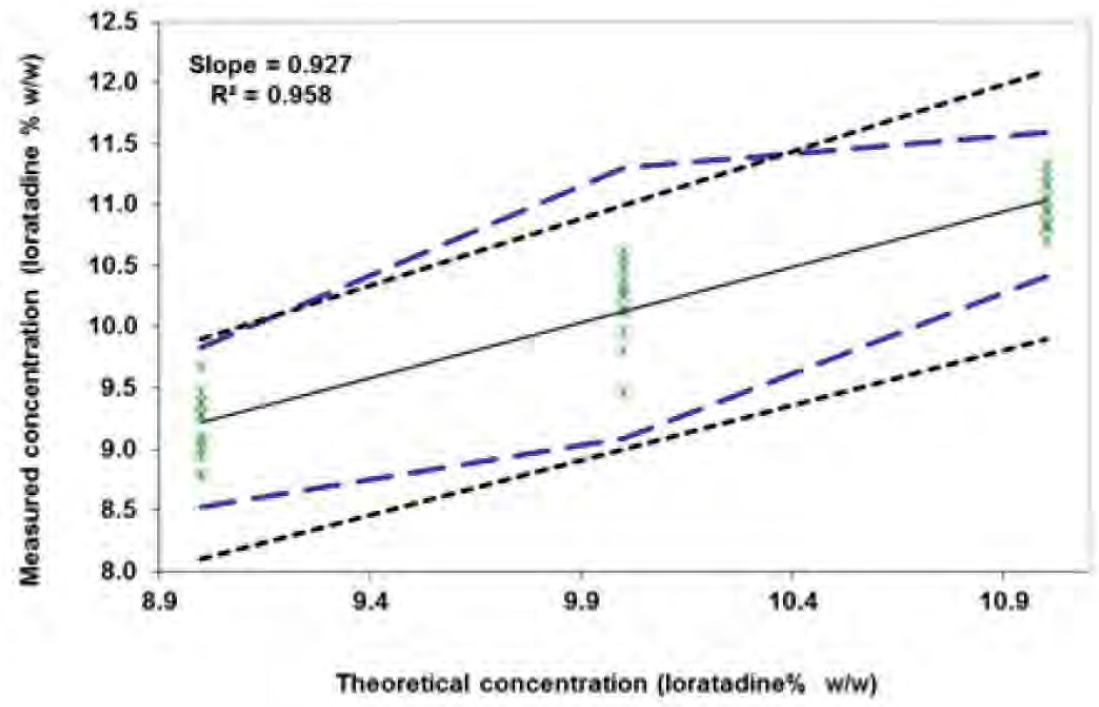

b) Tablets

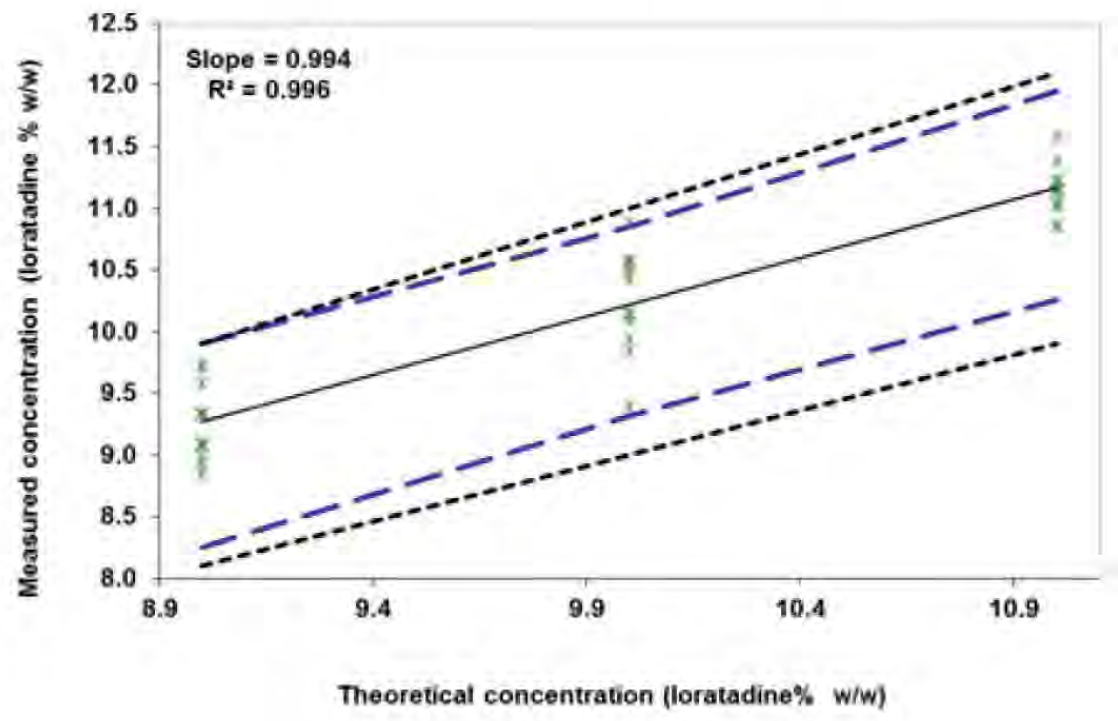

FIGURE 3. Linearity profiles obtained for the NIR-chemometric method for powder blends (a) and tablets (b)

of linearity, the value of $R^{2}$ is 0.958 and the slope is very close to 1 , confirming that the model is linear for loratadine assay. For the tablets, the best accuracy was obtained at the concentration level of $10 \mathrm{mg} / \mathrm{tablet}$ and the relative bias has values between $-0.360 \%$ and $0.618 \%$ for all the concentration levels. The value of $R^{2}$ is 0.996 and the slope is very close to 1 , confirming that the model is linear for loratadine assay. According to data obtained, the NIR-chemometric method has reproducibility and satisfactory accuracy and linearity profiles, indicating that this method could be used for direct determination of loratadine in powder blends for tableting and tablets with API ranging from 8 to $12 \mathrm{mg}$ loratadine/ formulation.

NIR spectroscopy combined with chemometrics has been used for the determination of different pharmaceutical properties of powders, granules, and tablets as it provides an ideal method of extracting quantitative information from samples (29). Maggio et al. used a NIRS method in order to perform a nondestructive determination of drug content in tablets with less than $1 \%$ weight of active ingredient per weight of formulation $(\mathrm{m} / \mathrm{m})$, showing that transmission NIR spectroscopy is a viable alternative for nondestructive testing of low drug content tablets. Different drug concentration ratios $\sim 0.5 \%, 0.7 \%$, and $1.0 \%(\mathrm{~m} / \mathrm{m})$ and ranging in drug content from 0.71 to $2.51 \mathrm{mg}$ per tablet were used in order to manufacture tablets. The calibration model developed with partial least squares regression included spectra from 110 tablets, with the spectral range from 11,216 to $8,662 \mathrm{~cm}^{-1}$ and the SNV and FD spectral pretreatments. This model was used to predict an independent set of 48 tablets with a root mean standard error of prediction (RMSEP) of $0.14 \mathrm{mg}$ and a bias of only $-0.05 \mathrm{mg}$ per tablet (30).

Tomuta et al. implemented and validated a NIR-chemometric method for the direct and simultaneous quantification of atorvastatin and amlodipine in pharmaceutical powder blends for tableting $(31,32)$. The calibration model used for the quantification of atorvastatin was developed using FD followed by SNV preprocessing method, 3 PLS factors and 4 spectral regions: $10,000-8,270 \mathrm{~cm}^{-1}$; $7,700-7,120 \mathrm{~cm}^{-1} ; 6,800-5,616 \mathrm{~cm}^{-1}$ and $5,400-4,243 \mathrm{~cm}^{-1}$. For the quantification of amlodipine the best predictive model was developed using the same preprocessing method, 6 PLS factors and 3 spectral regions: $10,000-$ $7,985 \mathrm{~cm}^{-1} ; 6,464-5,446 \mathrm{~cm}^{-1}$ and $4,605-4,020 \mathrm{~cm}^{-1}$. For both $\mathrm{API}$, the best accuracy was obtained at the medium concentration level with a 
bias of 0.492 for atorvastatin and -0.454 for amlodipine respectively. The value of $R^{2}$ was 0.963 for atorvastatin and 0.997 for amlodipine and both slopes were very close to 1 .

Compared to these similar studies that employed NIR spectroscopy combined with chemometrics, the method developed by our team is reproducible, precise and has satisfactory accuracy and linearity profiles, indicating that this method could be used for direct determination of loratadine in powder blends for tableting and tablets.

Compared to the current HPLC methods used for the analysis of loratadine in either powder blends or tablets $(16,17,18)$. the NIR method developed has the advantage of requiring no sample preparation and is nondestructive. Moreover, it can be used for on-line, in- line or at-line testing, while HPLC analysis can only be done off-line (29). The limits of quantification for the current HPLC method range between 124.6 and $373.8 \mu \mathrm{g} / \mathrm{ml}$, the method being considered a very sensitive analytical technique for determination of loratadine. The reported values of $R^{2}=0.999$, the recovery of $98.6 \%$ and a coefficient of variation $\mathrm{RSD}=1.7 \%$ prove that the HPLC method is linear and has good accuracy and precision (17).

Considering the developed NIR chemometric method for loratadine assay has a good similarity with the
HPLC method, we draw the conclusion that the method could be a viable alternative for the conventional methods since it is faster than conventional techniques and does not require any sample preparation.

\section{CONCLUSIONS}

Developing and validating a NIR-chemometric method for the direct quantification of loratadine from powder blends for tableting and tablets, without any sample preparation, was the main purpose of this work. In order to achieve this, different pre-processing methods were applied to the recorded spectra, the most predictive calibration model was further used to validate the method, according to the $\mathrm{ICH}$ guidance, and included accuracy, precision, linearity and range of application. Validation results showed satisfactory precision, trueness and linearity for the determination of loratadine from both powder blends for tableting and tablets with contents ranging between 80 and $120 \%$ API.

The NIR-chemometric method developed allows direct quantification of loratadine without any sample preparation and it could be used for both at line/in line monitoring of the manufacturing process of loratadine tablets through direct compression, achieving the goals of PAT and QbD concept.

Conflict of interest: none declared Financial support: none declared 
1. Anderson CA, Drennen JK, Ciurczak EW. Pharmaceutical applications of nearinfrared spectroscopy, in Handbook of Near-Infrared Analysis, D.A. Burns, E.W. Ciurczak, Eds., Taylor \& Francis Group, New York, US, 2008, p. 585-612.

2. Hart JR, Norris KH, Golumbic C. Determination of the Moisture Content of Seeds by Near-Infrared Spectrophotometry of Their Methanol Extracts. Cereal Chem. 1962;39:94-99.

3. Reich G. Near-infrared spectroscopy and imaging: basic principles and pharmaceutical applications. Adv Drug Deliv Rev. 2005;57(8):1109-1143.

4. De Beer T, Burggraeve A, Fonteyne M, Saerens L, Remon JP, Vervaet C. Near infrared and Raman spectroscopy for the in-process monitoring of pharmaceutical production processes. Int J Pharm. 2011;417(1-2):32-47.

5. Rosa SS, Barata PA, Martins JM, Menezes JC. Development and validation of a method for active drug identification and content determination of ranitidine in pharmaceutical products using nearinfrared reflectance spectroscopy: A parametric release approach. Talanta. 2008;75(3):725-33.

6. Marić LB, Jović BD, Petrović SD, Nikolić AM, Homšek IJ. The application of NIR spectroscopy with chemometric analysis for monitoring the powder blending process. J Serb Chem Soc 2014;79:331-340.

7. Jamrógiewicz M. Application of the near-infrared spectroscopy in the pharmaceutical technology. J Pharm Biomed Anal. 2012;66:1-10.

8. Roggo $Y$, Chalus $P$, Maurer L, Lema-Martinez C, Edmond A, Jent N. A review of near infrared spectroscopy and chemometrics in pharmaceutical technologies. J Pharm Biomed Anal. 2007;44(3):683-700.

9. Blanco M, Peguero A. Analysis of pharmaceuticals by NIR spectroscopy without a reference method. Trends. Anal. Chem. 2010;29:1127-1136.

10. Mabrouk MM, el-Fatatry HM, Hammad S, Wahbi AA. Simultaneous determination of loratadine and pseudoephedrine sulfate in pharmaceutical formulation by RP-LC and derivative spectrophotometry. J Pharm Biomed Anal. 2003;33(4):597-604.

11. Basavaiah K, Charan VS. Spectrophotometric determination of astemizole and loratadine based on charge-transfer complex formation with chloranilic acid. ScienceAsia 2002;28:359364.

12. Gazy AA, Mahgoub H, El-Yazbi FA, El-Sayed MA, Youssef RM. Determination of some histamine H1-receptor antagonists in dosage forms. J Pharm Biomed Anal. 2002;30(3):859-867.

13. El-Kousy N, Bebawy LI. Determination of some antihistaminic drugs by atomic absorption spectrometry and colorimetric methods. J Pharm Biomed Anal. 1999;20(4):671-679.

14. Indrayanto G, Darmawan L, Widjaja S, Noorrizka G. Densitometric determination of loratadine in pharmaceutical preparations, and validation of the method J. Planer Chromatogr. TLC 1999;12(4):261264.

15. Fernández H, Rupérez FJ, Barbas C. Capillary electrophoresis determination of loratadine and related impurities. J Pharm Biomed Anal. 2003;31(3):499-506.

16. El-Sherbiny DT, El-Enany N, Belal FF, Hansen $\mathrm{SH}$. Simultaneous determination of loratadine and desloratadine in pharmaceutical preparations using liquid chromatography with a microemulsion as eluent. J Pharm Biomed Anal. 2007;43(4):1236-1242.

17. Rupérez FJ, Fernández $\mathrm{H}$, Barbas C. LC determination of loratadine and related impurities. J Pharm Biomed Anal. 2002;29(1-2):35-41.

18. Porfire A, Filip C, Tomuta I. High-throughput NIR-chemometric methods for chemical and pharmaceutical characterization of sustained release tablets. J Pharm Biomed Anal. 2017:138:1-13.

19. De Bleye C, Chavez PF, Mantanus J, Marini $R$, Hubert $P$, Rozet $E$, Ziemons E. Critical review of near-infrared spectroscopic methods validations in pharmaceutical applications. J Pharm Biomed Anal. 2012;69:125-132.

20. Hubert $P$, Nguyen-Huu JJ, Boulanger $B$, Chapuzet E, Chiap P, Cohen N, Compagnon PA, Dewé W, Feinberg M, Lallier $M$, Laurentie M, Mercier N, Muzard G, Nivet C, Valat L. Harmonization of strategies for the validation of quantitative analytical procedures. A SFSTP proposal - Part I. J Pharm Biomed Anal. 2004;36(3):579-86.

21. Hubert $P$, Nguyen-Huu JJ, Boulanger $B$, Chapuzet E, Chiap P, Cohen N, Compagnon $P A$, Dewé $W$, Feinberg $M$, Lallier $M$, Laurentie M, Mercier N, Muzard G, Nivet C, Valat L, Rozet E. Harmonization of strategies for the validation of quantitative analytical procedures. A SFSTP proposal - Part II. J Pharm Biomed Anal. 2007;45(1):70-81.

22. Hubert $P$, Nguyen-Huu JJ, Boulanger $B$, Chapuzet E, Cohen N, Compagnon PA, Dewé $W$, Feinberg $M$, Laurentie $M$, Mercier $\mathrm{N}$, Muzard G, Valat L, Rozet E. Harmonization of strategies for the validation of quantitative analytical procedures. A SFSTP proposal - part III. J Pharm Biomed Anal. 2007;45(1):82-96.

23. Gavan A, Sylvester B, Casian T, Tomuta I. In-line fluid bed granulation monitoring by NIR spectroscopy. Method development and validation. Farmacia. 2019;67(2):248-257.

24. Roggo $Y$, Chalus $P$, Maurer L, Lema-Martinez C, Edmond A, Jent N. A review of near infrared spectroscopy and chemometrics in pharmaceutical technologies. J Pharm Biomed Anal. 2007;44(3):683-700.

25. *** ICH Harmonized Tripartite guideline: Pharmaceutical Development, Q8(R2), http://www.ich.org/fileadmin/Public_Web_ Site/ICH_Products/Guidelines/Quality/ Q8_R1/Step4/Q8_R2_Guideline.pdf (12.08.2020).

26. Mantanus J, Ziémons $E$, Lebrun $P$, Rozet $E$, Klinkenberg R, Streel B, Evrard B, Hubert P. Active content determination of noncoated pharmaceutical pellets by near infrared spectroscopy: method development, validation and reliability evaluation. Talanta. 2010;80(5):1750-1757.

27. Gavan A, Colobatiu L, Mocan A, Toiu A, Tomuta I. Development of a NIR Method for the In-Line Quantification of the Total Polyphenolic Content: A Study Applied on Ajuga genevensis L. Dry Extract Obtained in a Fluid Bed Process. Molecules. 2018;23(9):2152.

28. Tomuta I, Rus L, lovanov R, Rus LL High-throughput NIR-chemometric methods for determination of drug content and pharmaceutical properties of indapamide tablets. J Pharm Biomed Anal. 2013;84:285-292.

29. Singh I, Juneja P, Kaur B, Kumar P. Pharmaceutical Applications of Chemometric Techniques. ISRN Anal. Chem. 2013 Article ID 795178.

30. Maggio MR, Rivero MA, Kaufman ST. Simultaneous acquisition of the dissolution curves of two active ingredients in a binary pharmaceutical association, employing an on-line circulation system and chemometrics-assistance. J Pharm Biomed Anal. 2013;72:51-58.

31. Vonica-Gligor AL, Casian T, Reznek A, Tomuta I, Gligor F. Simultaneous quantification of atorvastatin and amlodipine in powder blends for tableting by NIR spectroscopy and chemometry. Farmacia 2015;63(3): 381-387.

32. Casian T, Reznek A, Vonica-Gligor LA, Van Renterghem J, De Beer T, Tomuta I. Development, validation and comparison of Near Infrared and Raman spectroscopic methods for fast characterization of tablets with amlodipine and valsartan. Talanta 2017;167:333-343. 